\title{
Detecting occult coronary artery disease followed by early coronary artery bypass surgery in patients with diabetic retinopathy: Report from a diabetic retinocoronary clinic
}

Takayuki Ohno, MD, PhD, ${ }^{a}$ Osamu Kinoshita, MD, ${ }^{\text {a }}$ Hideo Fujita, MD, PhD, ${ }^{\mathrm{b}}$ Satoshi Kato, MD, PhD, ${ }^{\mathrm{c}}$ Akira Hirose, MD, PhD, ${ }^{\mathrm{c}}$ Takashi Sigeeda, MD, PhD, ${ }^{\mathrm{c}}$ Kazuyoshi Otomo, MD, ${ }^{\mathrm{c}}$ Jiro Ando, MD, PhD, ${ }^{\mathrm{b}}$ Takashi Kadowaki, MD, PhD, ${ }^{\mathrm{d}}$ Makoto Araie, $\mathrm{MD}, \mathrm{PhD},{ }^{\mathrm{c}}$ Ryozo Nagai, $\mathrm{MD}, \mathrm{PhD},{ }^{\mathrm{b}}$ and Shinichi Takamoto, MD, $\mathrm{PhD}^{\mathrm{a}}$

Objectives: We hypothesized that a large number of patients with diabetic retinopathy who could benefit greatly from early coronary artery bypass grafting would not be identified.

Methods: Patients with diabetic retinopathy receiving ophthalmologic care as outpatients in our hospital in whom coronary artery disease was not previously suspected were referred randomly to the diabetic retinocoronary clinic and were asked to participate in diagnostic tests, including an exercise treadmill test and exercise thallium scintigraphy or coronary computed tomography. Patients who had type 1 diabetes mellitus, required hemodialysis, or both were excluded from this study. A definitive diagnosis of coronary artery disease was confirmed by means of coronary angiography.

Results: Of 214 patients with diabetic retinopathy, 55 (25.7\%) were confirmed as having significant stenotic coronary artery disease. Patients with angiographically confirmed coronary disease were older than those with negative results on diagnostic tests $(62.2 \pm 9.8$ vs $57.9 \pm 10.3$ years, $P=.01)$. Fifteen had 1 -vessel disease, 17 had 2-vessel disease, 14 had 3-vessel disease, 1 had left main trunk plus 1-vessel disease, 2 had left main trunk plus 2-vessel disease, and 5 had left main trunk plus 3-vessel disease. Eight patients had left main trunk disease, and 18 patients with non-left main trunk disease had proximal left anterior descending coronary artery (LAD) disease. Forty-two patients showed indications of coronary revascularization (coronary artery bypass grafting in 17 and percutaneous coronary intervention in 25). During the entire follow-up (287.6 \pm 183.2 days) of 39 patients undergoing coronary revascularization, all were alive without myocardial infarction, but 8 experienced vitreous hemorrhage.

Conclusions: Approximately $25 \%$ of patients with diabetic retinopathy receiving ophthalmologic care as outpatients have a significant stenotic coronary artery disease. Of the total diabetic population, a large number of patients with diabetic retinopathy who show strong indications for early coronary artery bypass grafting might well go unrecognized. (J Thorac Cardiovasc Surg 2010;139:92-7)

Coronary artery disease (CAD) is the leading cause of death in diabetic patients, accounting for $75 \%$ of deaths. ${ }^{1}$ The risk of CAD events varies widely from patient to patient and even within a diabetic patient as the disease progresses. Diabetic retinopathy (DR) is an early sign of microvascular complication of diabetes, its severity being directly related to the duration of the diabetes and to the amount of increase in blood glucose concentration. ${ }^{2}$ Evidence demonstrates that the severity of DR is associated with a graded increased risk of myocardial infarction and death from $\mathrm{CAD} .^{3-11}$

From the Departments of Cardiothoracic Surgery, ${ }^{\mathrm{a}}$ Cardiology, ${ }^{\mathrm{b}}$ Ophthalmology, ${ }^{\mathrm{c}}$ Endocrinology and Metabolism, ${ }^{\mathrm{d}}$ the University of Tokyo, Tokyo, Japan.

Received for publication Nov 30, 2008; revisions received March 19, 2009; accepted

for publication April 1, 2009; available ahead of print June 18, 2009.

Address for reprints: Takayuki Ohno, MD, PhD, Department of Cardiothoracic Sur-

gery, the University of Tokyo, Tokyo, Japan, 7-3-1, Hongo, Bunkyo-Ku, Tokyo,

113-8655, Japan (E-mail: takohno-tky@umin.net).

$0022-5223 / \$ 36.00$

Copyright (c) 2010 by The American Association for Thoracic Surgery

doi:10.1016/j.jtcvs.2009.04.005
We reviewed the literature regarding the association between DR and CAD and hypothesized that a large number of patients with DR and CAD who could benefit greatly from early coronary artery bypass grafting $(\mathrm{CABG})$ would not be identified until the occurrence of a catastrophic event, such as overt heart failure or sudden death. ${ }^{12}$ In this regard we opened a novel clinic named the diabetic retinocoronary clinic for the purpose of identification and treatment of occult CAD in patients with DR, and this article reports our experience in this clinic.

\section{MATERIALS AND METHODS \\ Study Patients}

The concept of a diabetic retinocoronary clinic was approved by the University of Tokyo Institutional Board for Outpatients in December 2006, and the clinic was opened in April 2007. Patients with DR receiving ophthalmologic care as outpatients in our hospital in whom CAD had not previously been suspected were referred randomly to the clinic by ophthalmologists or endocrinologists. Patients who had type 1 diabetes mellitus, required hemodialysis, or both were excluded from this study. All patients provided informed consent 

Abbreviations and Acronyms
$\mathrm{CABG}=$ coronary artery bypass grafting
$\mathrm{CAD}=$ coronary artery disease
$\mathrm{CT}=$ computed tomography
DES = drug-eluting stent
DR $=$ diabetic retinopathy
ECG = electrocardiography
ETT $=$ exercise treadmill test
LAD $=$ left anterior descending coronary artery
LMT = left main trunk
NPDR $=$ nonproliferative diabetic retinopathy
PCI = percutaneous coronary intervention
$\mathrm{PDR}=$ proliferative diabetic retinopathy

One hundred seventy-six $(82.2 \%)$ patients were completely asymptomatic; $25(11.7 \%)$ were revealed during history taking by cardiac surgeons and cardiologists to have chest discomfort, but their symptoms were not typical of angina pectoris. Furthermore, limited physical activity prevented a precise evaluation of angina pectoris in $11(5.1 \%)$ patients with severely impaired vision and in $2(0.9 \%)$ patients with peripheral arterial disease. Of the study group, normal resting ECG results were seen in 159 (74.3\%), Q waves were seen in $4(1.9 \%)$, nonspecific ST-T changes were seen in $39(18.2 \%)$, right bundle branch block was seen in 9 $(4.2 \%)$, atrial fibrillation was seen in $2(0.9 \%)$, and second-degree atrioventricular block was seen in $1(0.5 \%)$.

Of the 172 patients undergoing ETT, $50(29.1 \%)$ had a positive ETT result, $106(61.7 \%)$ had a negative ETT result, and $15(8.7 \%)$ had nondiagnostic results. The patients who had limitations that precluded the ETT $(n=42)$ or had nondiagnostic results on the ETT were approached for exercise thallium scintigraphic analysis or coronary CT scanning. Thirty-three patients underwent exercise thallium scintigraphy, and $8(24.2 \%)$ had abnormal results. Twenty-four patients underwent coronary $\mathrm{CT}$, which revealed atherosclerotic CAD in $7(29.2 \%)$.

Sixty-five patients underwent coronary angiography. Overall, of 214 study patients, $55(25.7 \%)$ were confirmed as having significant stenotic CAD (Figure 1). The baseline characteristics of the patients with an angiographically confirmed CAD were compared with those of patients with negative results on diagnostic tests (Table 1). Patients with angiographically confirmed CAD were older $(62.2 \pm 9.8$ vs $57.9 \pm 10.3$ years, $P=.01)$. Twenty $(46.5 \%)$ of 43 patients with Q-wave or ST-T changes on resting ECGs had CAD, whereas $35(20.5 \%)$ of 171 patients without these abnormalities had $\operatorname{CAD}(P=.001)$. The serum creatinine level, estimated glomerular filtration rate, hemoglobin A1c level, low-density lipoprotein level, and high-density lipoprotein level were similar in the 2 groups. Neither the severity of DR nor treatment with insulin was associated with angiographically confirmed CAD.

Of the 55 patients with CAD, $8(14.5 \%)$ had LMT disease, $18(32.7 \%)$ patients without LMT disease had proximal LAD disease, and 29 patients had non-LMT, nonproximal LAD disease (Figure 1). One-vessel disease was seen in $15(27.3 \%)$, 2-vessel disease was seen in 17 $(30.9 \%)$, 3-vessel disease was seen in $14(25.5 \%)$, LMT plus 1 -vessel disease was seen in $1(1.8 \%)$, LMT plus 2 -vessel disease was seen in $2(3.6 \%)$, and LMT plus 3 -vessel disease was seen in $5(9.1 \%)$ patients. In a daily coronary conference held within our institution, CABG was recommended for 17 patients, percutaneous coronary intervention (PCI) was recommended for 25 patients, and aggressive medical therapy alone was recommended for 13 patients. For all patients with LMT disease, coronary revascularization was indicated. Of 18 patients without LMT 


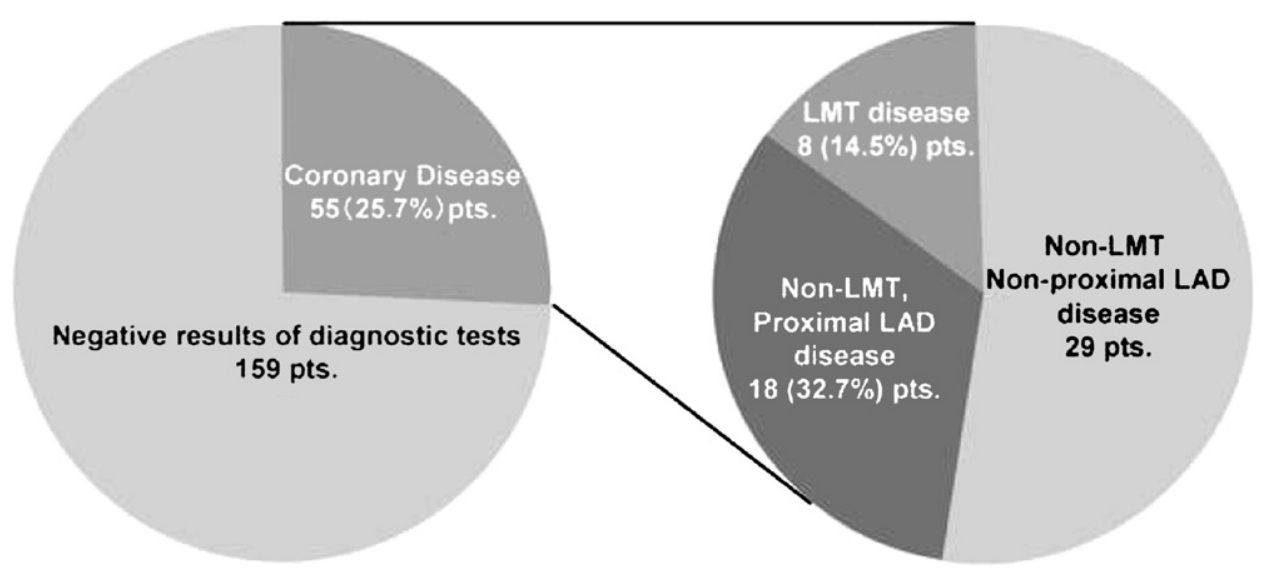

FIGURE 1. Incidence of occult coronary artery disease in 214 patients with diabetic retinopathy who were referred to the diabetic retinocoronary clinic. Fifty-five $(25.7 \%)$ patients had angiographically confirmed coronary artery disease. Eight $(14.5 \%)$ of them had left main trunk (LMT) disease, and 18 $(32.7 \%)$ had proximal left anterior descending coronary artery $(L A D)$ disease.

disease but with proximal LAD disease, 15 were considered to have indications for revascularization. Thus far, 12 have undergone $\mathrm{CABG}$, and 27 have undergone PCI. Three patients for whom CABG was recommended consented to undergo only PCI. Three refused coronary revascularization by means of either CABG or PCI. During the entire follow-up (287.6 \pm 183.2 days), from the initial coronary revascularization, all patients have remained alive without myocardial infarction. However, vitreous hemorrhage occurred in 4 patients with PDR receiving CABG and in 4 patients with PDR receiving PCI (Figure 2). No patients with NPDR experienced vitreous hemorrhage. The mean interval between the initial revascularization and the occurrence of vitreous hemorrhage was 118 days (range, 6-387 days). Six patients experienced vitreous hemorrhage within 6 months after the initial revascularization and 7 within 1 year after revascularization.

\section{DISCUSSION}

The present study revealed that of 214 patients with DR receiving ophthalmologic outpatient care, $55(25.7 \%)$ had angiographically confirmed significant stenotic CAD, and $26(12.1 \%)$ had LMT disease, proximal LAD disease, or both. In $42(19.6 \%)$ patients coronary revascularization was indicated. These findings suggest that a large number of patients with DR and CAD could go unrecognized until the arrival of a catastrophic event, such as overt heart failure or sudden death.

Of the 214 study patients, 87 (40.7\%) were receiving insulin treatment, a proportion that seems high for patients with type 2 diabetes. All the study patients had DR, 59 diabetic patients had nonproliferative retinopathy, and 155 diabetic patients had proliferative retinopathy. Therefore our patients, especially those with proliferative retinopathy,

TABLE 1. Baseline characteristics of patients with diabetic retinopathy who were referred to the diabetic retinocoronary clinic*

\begin{tabular}{|c|c|c|c|}
\hline Characteristic & $\begin{array}{l}\text { Patients with angiographically } \\
\text { confirmed CAD }(n=55)\end{array}$ & $\begin{array}{c}\text { Patients with negative results on } \\
\text { diagnostic tests }(n=159)\end{array}$ & $P$ value \\
\hline Mean age (y) & $62.2 \pm 9.8$ & $57.9 \pm 10.3$ & .01 \\
\hline Female sex, no. $(\%)$ & $11(20.0)$ & $53(33.3)$ & .09 \\
\hline Height $(\mathrm{cm})$ & $163.0 \pm 8.2$ & $162.7 \pm 8.5$ & .87 \\
\hline Body weight $(\mathrm{kg})$ & $65.9 \pm 14.4$ & $66.3 \pm 13.9$ & .88 \\
\hline Body mass index & $24.8 \pm 4.8$ & $24.9 \pm 4.3$ & .94 \\
\hline NPDR, no. (\%) & $17(30.9)$ & $42(26.4)$ & .64 \\
\hline PDR, no. (\%) & $38(69.1)$ & $117(73.6)$ & .64 \\
\hline Treatment with insulin, no. (\%) & $21(38.2)$ & $66(41.5)$ & .75 \\
\hline Q-wave/ST-T change, no. (\%) & $20(36.4)$ & $23(14.5)$ & .001 \\
\hline Hemoglobin A1c (\%) & $7.3 \pm 1.7$ & $7.4 \pm 1.4$ & .56 \\
\hline Mean serum creatinine $(\mathrm{mg} / \mathrm{dL})$ & $0.94 \pm 0.52$ & $1.0 \pm 0.82$ & .58 \\
\hline eGFR (mL/min) & $69.0 \pm 19.8$ & $69.7 \pm 25.1$ & .86 \\
\hline BNP (pg/mL) & $43.7 \pm 79.2$ & $30.0 \pm 38.5$ & .10 \\
\hline Mean serum LDL (mg/dL) & $107.6 \pm 30.4$ & $109.2 \pm 33.6$ & .77 \\
\hline Mean serum HDL (mg/dL) & $55.8 \pm 26.3$ & $57.7 \pm 15.9$ & .59 \\
\hline Mean serum triglycerides $(\mathrm{mg} / \mathrm{dL})$ & $134.2 \pm 74.6$ & $135.2 \pm 81.8$ & .94 \\
\hline
\end{tabular}

Values are presented as means \pm standard deviations, where shown. $C A D$, Coronary artery disease; $N P D R$, nonproliferative diabetic retinopathy; $P D R$, proliferative diabetic retinopathy; $e G F R$, estimated glomerular filtration rate; $B N P$, B-type natriuretic peptide; $L D L$, low-density lipoprotein; $H D L$, high-density lipoprotein. 


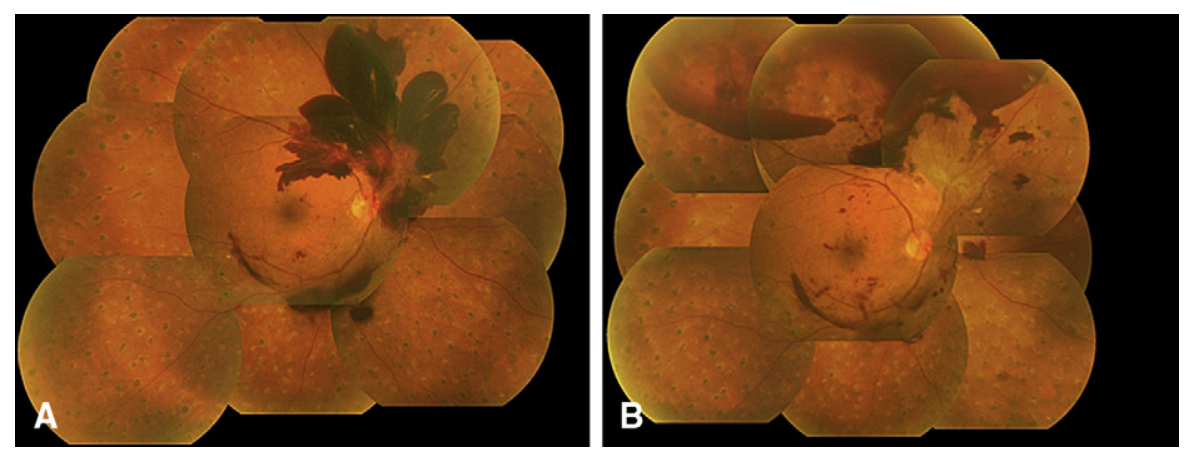

FIGURE 2. Vitreous hemorrhage in patients with diabetic retinopathy after drug-eluting stent implantation. Twenty-one days after drug-eluting stent implantation, a fundus photograph (A) revealed a considerable degree of vitreous hemorrhage in the right eye. Three months after drug-eluting stent implantation, the patient's vitreous hemorrhage shows no tendency to subside with continued dual-antiplatelet therapy (B).

were at severe stages of diabetes mellitus, and therefore the high prevalence of insulin treatment can be expected.

Most patients with DR who were referred to our diabetic retinocoronary clinic were asymptomatic. Few studies assessed the incidence of CAD in asymptomatic patients with DR with normal ECG results and indicated that approximately $20 \%$ of these patients had CAD. ${ }^{14-16}$ In the present study $20.5 \%$ of patients with DR without Q-wave or ST-T changes had angiographically confirmed CAD. The results of previous studies and our results correspond closely. One important issue is that identification of CAD is sometimes difficult, especially in patients with sight-threatening DR. Many patients with this condition have limited physical activity because of impaired vision. ${ }^{17-19}$ Limited physical activity clearly reduces the appreciation of ischemic pain and is attributed to the difficulty of evaluation of chest pain. In this study 11 patients had severely impaired vision, and therefore we could not evaluate their symptoms. One patient with PDR had previously had typical angina pectoris, but he said that his angina disappeared after vitreous hemorrhage. Furthermore, 4 patients in whom coronary revascularization was indicated refused it because they were completely free of angina pectoris.

In patients with $\mathrm{DR}$ and $\mathrm{CAD}$, the main treatment effect of coronary revascularization should be to prevent myocardial infarction and death from CAD. Evidence indicates that PCI does not reduce the risk of death or myocardial infarction in patients with stable CAD. ${ }^{20,21}$ In contrast, CABG confers survival benefit to high-risk patients, such as those with extensive coronary disease or diabetes mellitus. ${ }^{22,23}$ In addition, our previous study demonstrated that the survival benefit of CABG over PCI is more apparent in patients with DR than in diabetic patients without retinopathy. ${ }^{24}$ Overall consideration suggests that CABG should be the first choice for revascularization of patients with DR and CAD.

Previously, we demonstrated that long-term survival after CABG is closely related to the severity of DR and that patients with advanced DR have a poor prognosis. ${ }^{25,26}$ Furthermore, we showed that patients with NPDR have a greater risk of target-vessel failure (defined as a composite of cardiac death, myocardial infarction, and target-vessel revascularization) after drug-eluting stent (DES) implantation. ${ }^{27}$ In this study the prevalence of angiographically confirmed CAD was similar in patients with NPDR $(28.8 \%)$ and in those with PDR (24.5\%). However, the association between the severity of DR and the extent of CAD were not evaluated in this study. Nargaz and colleagues ${ }^{28}$ demonstrated that the diffuse nature of CAD is associated with the severity of DR. We postulate that detecting occult CAD followed by CABG would confer survival benefit effectively in patients with DR, especially in the early stage.

Vitreous hemorrhage is a sight-threatening complication in patients with DR and requires vitreous surgery in persistent cases. Progression of DR involving vitreous hemorrhage can take place spontaneously in diabetic patients after coronary revascularization with either PCI or CABG, but little about the prevalence of vitreous hemorrhage after coronary revascularization is known. ${ }^{29-31}$ A large number of patients with DR who are at risk of vitreous hemorrhage appear to undergo coronary revascularization. Therefore the issue of postrevascularization vitreous hemorrhage is an important one for both cardiologists and cardiac surgeons. This study revealed that vitreous hemorrhage after coronary revascularization was unexpectedly high in patients with PDR. Of 24 patients with PDR undergoing coronary revascularization, $6(25 \%)$ had vitreous hemorrhage within 6 months after the initial revascularization. Our experience indicates that careful postoperative eye care is required. Figure 2 presents one case. The difficulty in treating vitreous hemorrhage after PCI with DES implantation is that prolonged dual-antiplatelet therapy is mandatory because of further potential risk for stent thrombosis. Therefore the future risk of vitreous hemorrhage might influence the choice of revascularization strategy for patients with DR, and DES implantation might not be indicated in patients with PDR.

In 2005, the Japanese Ophthalmologists Association announced that approximately 3 million Japanese people between the ages of 50 and 69 years have DR. In the present 
study $12.1 \%$ of patients with DR in whom CAD was not suspected had LMT, proximal LAD disease, or both. Theoretically, CABG with an internal thoracic artery graft confers the survival benefit effectively in patients with LMT disease, proximal LAD disease, or both. Therefore 363,000 patients in Japan can be expected to benefit greatly from early CABG. On the other hand, annually, approximately 20,000 patients in Japan undergo CABG; in other words, 4000 patients with DR undergo CABG per year. These estimates suggest that a large number of patients with DR in whom the survival chances can be improved by CABG would remain without diagnoses until a fatal coronary event. We think that this specialized clinic might become the new model of an institution for identifying occult CAD in patients with DR requiring CABG.

The present study has some caveats. First, this study did not include diabetic patients without retinopathy. Therefore we did not estimate the relative risk of occult CAD in patients with DR compared with that in seen diabetic patients without retinopathy. Previous studies have demonstrated that the incidence of occult CAD in diabetic patients without retinopathy has ranged from $1.5 \%$ to $8.5 \% \cdot{ }^{14-16}$ In addition, the previous studies have shown that the risk of cardiac events in diabetic patients without retinopathy is lower than that seen in patients with DR. ${ }^{3-11}$

Second, we used ETT as a diagnostic test for CAD screening in patients in whom ETT was not precluded. Therefore, some patients with negative results on diagnostic tests might have a significant stenotic CAD.

Third, in this study the survival data of patients with negative diagnostic test results were not obtained. The mean follow-up duration of patients with CAD since the initial admission to our clinic was 415 days, and no one died during this period. Therefore, long-term follow-up might be required to evaluate the survival benefit of early CABG.

Finally, in Japan medical costs are 3200 yen for ETT, 33,000 yen for coronary CT, and 94,000 yen for exercise thallium scintigraphy. Further study is needed regarding cost-effective analysis of our proactive strategy.

While acknowledging these caveats, we believe that the incidence of CAD in patients with DR seems very high, and we believe that targeting patients with DR among the general population of diabetic patients would be a useful strategy for improving the life expectancy of the overall diabetic population.

\section{References}

1. Bonow RO, Bohannon N, Hazzard W. Risk stratification in coronary artery disease and special populations. Am J Med. 1996;101(suppl):17S-22S.

2. Ferris FL III, Davis MD, Aiello LM. Treatment of diabetic retinopathy. $N$ Engl J Med. 1999;341:1127-33.

3. Klein R, Klein BE, Moss SE, Cruickshanks KJ. Association of ocular disease and mortality in a diabetic population. Arch Ophthalmol. 1999;117:1487-95.

4. Klein BE, Klein R, McBride PE, Cruickshanks KJ, Palta M, Knudtson MD, et al. Cardiovascular disease, mortality, and retinal microvascular characteristics in type 1 diabetes: Wisconsin epidemiologic study of diabetic retinopathy. Arch Intern Med. 2004;164:1917-24.

5. Henricsson M, Nilsson A, Heiji A, Janzon L, Groop L. Mortality in diabetic patients participating in an ophthalmological control and screening programme. $D i$ abet Med. 1997; 14:576-83.

6. Mittinen H, Haffner SM, Lehto S, Ronnemaa T, Pyorala K, Laakso M. Retinopathy predicts coronary heart disease events in NIDDM patients. Diabetes Care. 1996;19:1445-8.

7. Faglia E, Favales F, Calia P, Paleari F, Seqalini G, Gamba PL, et al. Cardiac events in 735 type 2 diabetic patients who underwent screening for unknown asymptomatic coronary heart disease: 5-year follow-up report from Milan Study on Atherosclerosis and Diabetes (MiSAD). Diabetes Care. 2002;25:2032-6.

8. Torffvit O, Lövestam-Adrian M, Agardh E, Agardh CD. Nephropathy, but not retinopathy, is associated with the development of heart disease in type 1 diabetes: a 12-year observation study of 462 patients. Diabet Med. 2005;22:723-9.

9. Soedamah-Muthu SS, Chaturvedi N, Toeller M, Toeller M, Ferris B, Redoldi P, et al. Risk factors for coronary heart disease in type 1 diabetic patients in Europe: the EURODIAB Prospective Complications Study. Diabetes Care. 2004;27: 530-7.

10. Juutilainen A, Lehto S, Ronnemaa T, Pyorala K, Laakso M. Retinopathy predicts cardiovascular mortality in type 2 diabetic men and women. Diabetes. 2007;30: 292-9.

11. Cheung N, Wang JJ, Klein R, Coupep D, Sharrett AR, Wong TY. Diabetic retinopathy and the risk of coronary heart disease: the Atherosclerosis risk in Communities Study. Diabetes Care. 2007;30:1742-6.

12. Ohno T, Takamoto S, Motomura N. Diabetic retinopathy and coronary artery disease: from the cardiac surgeon's perspective. Ann Thorac Surg. 2008;85: 681-9.

13. Gibbons RJ, Balady GJ, Beasley JW, Bricker JT, Duvernoy WFC, Froelicher VF, et al. ACC/AHA Guidelines for Exercise Testing: a report of the American College of Cardiology/American Heart Association Task Force on Practice Guidelines (Committee on Exercise Testing). J Am Coll Cardiol. 1997;30:260-315.

14. Janand-Delenne B, Savin B, Habib G, Bory M, Vague P, Lassmann-Vague V. Silent myocardial ischemia in patients with diabetes: who to screen. Diabetes Care. 1999;22:1396-400.

15. Gokcel A, Aydin M, Yalcin F, Yapar AF, Ertorer ME, Ozsahin AK, et al. Silent coronary artery disease in patients with type 2 diabetes mellitus. Acta Diabetol. 2003;40:176-80.

16. Araz M, Celen Z, Akdemir I, Okan V. Frequency of silent myocardial ischemia in type 2 diabetic patients and the relation with poor glycemic control. Acta Diabetol. 2004;41:38-43.

17. Woodcock A, Bradley C, Plowright R, ffytche T, Kennedy-Martin T, Hirsch A. The influence of diabetic retinopathy on quality of life: interviews to guide the design of a condition-specific, individualised questionnaire: the RetDQoL. Patient Educ Couns. 2004;53:365-83.

18. Bailey CC, Sparrow JM. Visual symptomatology in patients with sight-threatening diabetic retinopathy. Diabet Med. 2001;18:883-8.

19. Coyne KS, Margolis MK, Kennedy-Martin T, Baker TM, Klein R, Paul MD, et al. The impact of diabetic retinopathy: perspectives from patient focus groups. Fam Pract. 2004;21:447-53.

20. Katritsis DG, Ioannidis JP. Percutaneous coronary intervention versus conservative therapy in nonacute coronary artery disease: a meta-analysis. Circulation. 2005; 111:2906-12.

21. Boden WE, O'Rourke RA, Teo KK, Hartigan PM, Maron DJ, Kostuk WJ, et al. Optimal medical therapy with or without PCI for stable coronary disease. $N$ Engl $J$ Med. 2007;356:1503-16.

22. Yusuf S, Zucker D, Peduzzi P, Fisher LR, Takaro T, Kennedy JW, et al. Effect of coronary artery bypass graft surgery on survival: overview of 10-year results from randomized trials by the Coronary Artery Bypass Graft Surgery Trialists Collaboration. Lancet. 1994;344:563-70.

23. BARI Investigators. The final 10-year follow-up results from the BARI randomized trial. J Am Coll Cardiol. 2007;49:1600-6.

24. Ohno T, Ando J, Ono M, Morita T, Motomura N, Hirata Y, et al. The Beneficial effect of coronary-artery-bypass surgery on survival in patients with diabetic retinopathy. Eur J Cardiothorac Surg. 2006;30:881-6.

25. Ono T, Kobayashi J, Sasako Y, Bando K, Tagusari O, Niwaya K, et al. The impact of diabetic retinopathy on long-term outcome following coronary artery bypass graft surgery. J Am Coll Cardiol. 2002;40:428-36.

26. Ono T, Ohashi T, Asakura T, Ono N, Ono M, Motomura N, et al. Impact of diabetic retinopathy on cardiac outcome after coronary artery bypass graft surgery: 
prospective observational study. Ann Thorac Surg. 2006;81:608-12.

27. Ohno T, Takamoto S, Ando J, Morita T, Fujita H, Hirata Y, et al. Diabetic retinopathy and coronary implantation of sirolimus-eluting stents. J Interven Cardiol. 2007;20:1-10.

28. Norgaz T, Hobikoglu G, Aksu H, Guveli A, Aksoy S, Ozer O, et al. Retinopathy is related to the angiographically detected severity and extent of coronary artery disease in patients with type 2 diabetes mellitus. Int Heart J. 2005;46: 639-46.
29. Mansour AM, Awwad ST, Najjar DM, Sibai AN, Sibai AN, Medawar WA, et al. Anterior ischaemic optic neuropathy after coronary artery bypass graft: the role of anaemia in diabetics. Eye. 2006;20:706-11.

30. Chadha V, Styles C. Progression of diabetic retinopathy following coronary artery bypass graft. Eye. 2007;21:864-5.

31. Small KW, Buckley EG. The risk of vitreous hemorrhage caused by coronary artery bypass grafting in proliferative diabetic retinopathy. J Thorac Cardiovasc Surg. 1990;99:176-7. 